\title{
BRIDGE SURFACE DAMAGE DETECTION APPLICATION WITH A LASER-BASED SOFTWARE PROTOTYPE
}

\author{
B. Güldür Erkal ${ }^{\text {a }}$ N. M. Apaydın ${ }^{\text {b }}$

\begin{abstract}
${ }^{a}$ Assistant Professor, Department of Civil Engineering, Hacettepe University, Beytepe Campus, 06800 Çankaya, Ankara, Turkey burcuguldur@hacettepe.edu.tr

${ }^{\mathrm{b}}$ Associate Professor and Head of Structures Department, General Directorate of Highways, Republic of Turkey Ministry of Transportation and Maritime Affairs and Communication, 06100, Çankaya, Ankara, Turkey - napaydin@kgm.gov.tr
\end{abstract}

KEY WORDS: Terrestrial Laser Scanners, Texture-Mapped Point Clouds, Point Cloud Processing, Surface Damage Detection, Software Application

\begin{abstract}
:
In order to determine the necessary actions such as rehabilitation, repair and etc. required for maintaining the operating status of aging bridges, the current conditions of these structures need to be assessed. Terrestrial laser scanners that are used to capture texture-mapped point clouds have been frequently used for assessing the current conditions of these structures. Authors' have already developed surface damage detection algorithms in their previous work. The developed algorithms are capable of detecting several damage types from the collected texture-mapped point clouds. This short paper focuses on presenting the field application of a recently developed prototype software application that uses the previously developed surface damage detection algorithms. Capabilities of the prototype software application can be listed as importing point clouds, working with images, extracting damage features such as shape and size, determining condition ratings and producing damage reports for future investigations.
\end{abstract}

\section{INTRODUCTION AND BACKGROUND}

Terrestrial laser scanners possess the ability to capture the entire surface data of an investigated structure. Therefore, it is possible to develop new health monitoring methodologies that do not require mounted sensors on the structure. Researchers have been developing methodologies for using laser scanning technology for both monitoring structures and detecting damage in the last two decades (Lovas et al., 2008; Zogg, 2008; Olsen et al., 2009).

Even though the texture-mapped point clouds provide an opportunity to detect several damage types on an existing structure, their usage for damage detection is still not common. The authors' previous research (Guldur, 2014; Guldur and Hajjar, 2014) was focusing on developing both algorithms and strategies for detecting surface damage from captured texturemapped point clouds. The details of these algorithms and related strategies could be found in the listed references.

This short paper focuses on the field application of a recently developed software prototype, on which the authors' have been working on (Guldur Erkal, 2017), that utilizes the previously developed surface damage detection algorithms. The details of the developed software application are given in Section 2.

\section{DETAILS OF THE PROTOTYPE OF THE DEVELOPED SOFTWARE APPLICATION}

The developed software prototype is capable of directly on the texture-mapped point clouds. The users first upload the part of the point cloud that they would like to investigate for visualization purposes. The application also gives an option to the user for uploading images related to the damage region that are later included in the generated final report. The user is then given the option to select the investigated damage type. In order to perform damage detection, the software automatically asks for the user defined parameters. The software shows the condition rating and the related condition rating explanation on the screen. Finally, a report for the user is generated. This report includes the images related to the damage, the damage type, the damage features such as area and volume, the condition rating and the condition rating explanation for the detected damage. The condition rating of an investigated member is determined by comparing the current physical state of the structure to what it was on the day it started to service (the initial condition is predicted if there isn't enough information). Sample condition rating guidelines from different sources are adapted to classify the damage severity in a well-known format. As an example, Table 1, which is taken from Manual Bridge Inspection Manual of Ohio, gives the summary of condition rating guidelines for the deck, superstructure and substructure.

\section{FIELD APPLICATION AND RESULTS}

In order to verify capabilities of the developed software prototype, a field application has been performed. First, the texture-mapped point cloud of a selected bridge is captured. Then, a small region extracted from the deck was used to perform surface damage detection.

The bridge, which was laser-scanned for this field application, is the Çayırhan Bridge. This bridge is located on the state road, D140, that lays in between Ankara - Nallıhan, Turkey. The Çayırhan Bridge was built in 1955 and since then, it has been constantly operating. This bridge is a reinforced concrete arch bridge with a total deck length of $105.7 \mathrm{~m}$. The image of the bridge is given in Figure 1 and the captured point cloud is given in Figure 2. 


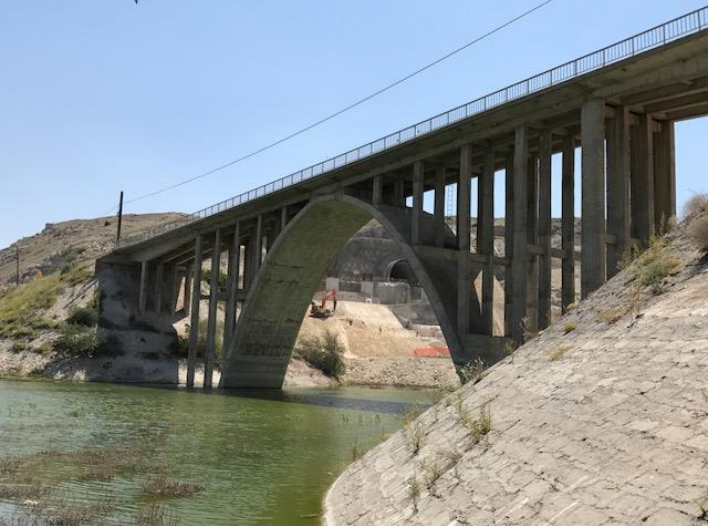

Figure 1: The image of the Çayırhan Bridge.

\begin{tabular}{|c|c|c|c|}
\hline \begin{tabular}{|c|}
$1-4$ \\
Worst \\
Span
\end{tabular} & \multicolumn{2}{|c|}{$\begin{array}{l}\text { NBIS 9-0 - Deck, Superstructure and Substructure } \\
\text { SUMMARY Hems } \\
\text { TOTAL BRIDGE }\end{array}$} & Inspector Guidelines \\
\hline & 9-Excellent & & \\
\hline & 8-Very Good & No problems noted & \\
\hline & 7.-Good & Some minor problems & Brief comments as appropriate \\
\hline & $\begin{array}{l}\text { 6- } \\
\text { Satisfactory }\end{array}$ & $\begin{array}{l}\text { Structural elements show some minor } \\
\text { deterioration }\end{array}$ & Comments as appropriate \\
\hline 2 & 5-Fair & $\begin{array}{l}\text { All primary structural elements are } \\
\text { sound but have minor section loss, } \\
\text { deterioration, spalling or scour }\end{array}$ & $\begin{array}{l}\text { Document deficiencies } \\
\text { quantitatively with descriptive } \\
\text { comments. }\end{array}$ \\
\hline & 4. Poor & $\begin{array}{l}\text { Advanced section loss, deterioration, } \\
\text { spalling or scour }\end{array}$ & $\begin{array}{l}\text { Candidate to establish monitoring } \\
\text { parameters with specific locations to } \\
\text { track the deficiencies rata-off-change } \\
\text { at the next inspection. In addition to } \\
\text { quantitative documentation take } \\
\text { photos, make skekcthes and or } \\
\text { establish monitoring control points. }\end{array}$ \\
\hline & 3-Serious & $\begin{array}{l}\text { Loss of section, deterioration, spalling } \\
\text { or scour has seriously affected primary } \\
\text { structural components. Local fialures } \\
\text { are possible. Fatigue cracks in steel or } \\
\text { shear cracks in concrete may be } \\
\text { present }\end{array}$ & \begin{tabular}{|l|} 
Document deficiencies \\
quantitatively with descriptive \\
comments; establish monitoring \\
benchmarks. Discuss with Program \\
Manager, structure may be prone to \\
localized failures.
\end{tabular} \\
\hline & 2-Critical & $\begin{array}{l}\text { Advanced deterioration of primary } \\
\text { structural clements. Fatigue cracks in } \\
\text { steel or shear cracks in concrete may } \\
\text { be present or scour may have removed } \\
\text { substructure support. Unless closely } \\
\text { monitored it may be necessary to close } \\
\text { the bridge until corrective action is } \\
\text { taken }\end{array}$ & $\begin{array}{l}\text { Document deficiencies } \\
\text { quantitatively with descriptive } \\
\text { comments; establish monitoring } \\
\text { benchmarks. Contact Program } \\
\text { Manager, candidate to dispatch } \\
\text { repairs and or road closure. } \\
\text { Confirm in writing. } \\
\end{array}$ \\
\hline 1 & $\begin{array}{l}\text { 1-Imminent } \\
\text { Failure }\end{array}$ & \begin{tabular}{|l|} 
Major deterioration or section loss \\
present in critical structural \\
components or bovious vertical or \\
horizontal movement affecting \\
structure stability. Bridge is closed to \\
traffic but corrective action may put \\
bridge back into light service
\end{tabular} & $\begin{array}{l}\text { Dispatch personnel for immediate } \\
\text { closure. Notify Program Manager. } \\
\text { Confirm in writing. }\end{array}$ \\
\hline & 0 - Failed & $\begin{array}{l}\text { Out of service - beyond corrective } \\
\text { action }\end{array}$ & \\
\hline
\end{tabular}

Table 1: Summary of condition rating guidelines for deck, superstructure and substructure (Ohio Department of Transportation., 2010).

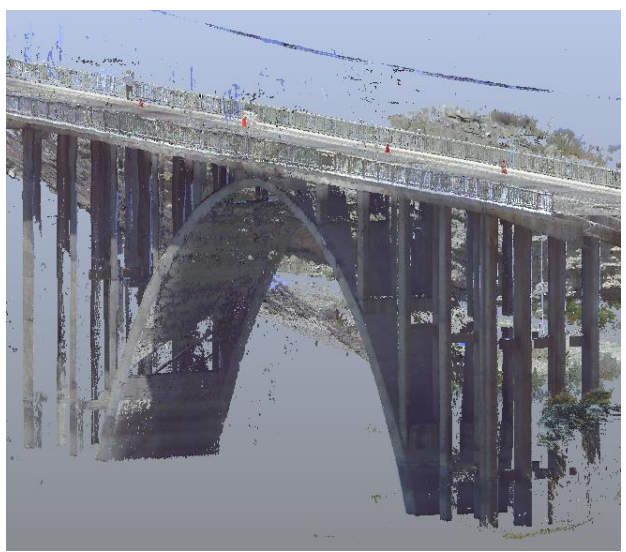

Figure 2: The texture-mapped point cloud of the Çayırhan Bridge.

As already mentioned, a portion of the deck has been extracted in order to perform surface damage detection by using the developed software prototype. The selected region is yellowmarked in Figure 3.

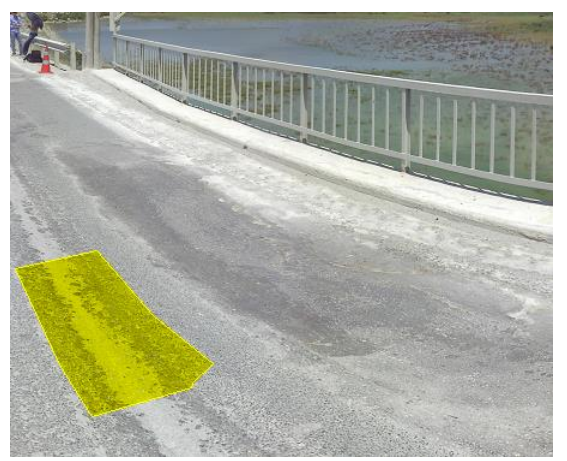

Figure 3: The selected region on the bridge deck for surface damage detection.

The texture-mapped point cloud of the selected region is uploaded in the software prototype. Then, the image that is marked with physical measurement locations is uploaded. The damage type is selected from the drop-down menu and the associated parameters, angle threshold and the intensity threshold, are inserted. The procedures for selecting these parameters are described in Guldur (2014). Finally, once the "Damage Detection" is completed, the damage detection results, the computed condition rating and the associated rating details are displayed on screen. The comparison between the field measurements and the computed surface damage dimensions are given in Table 2.

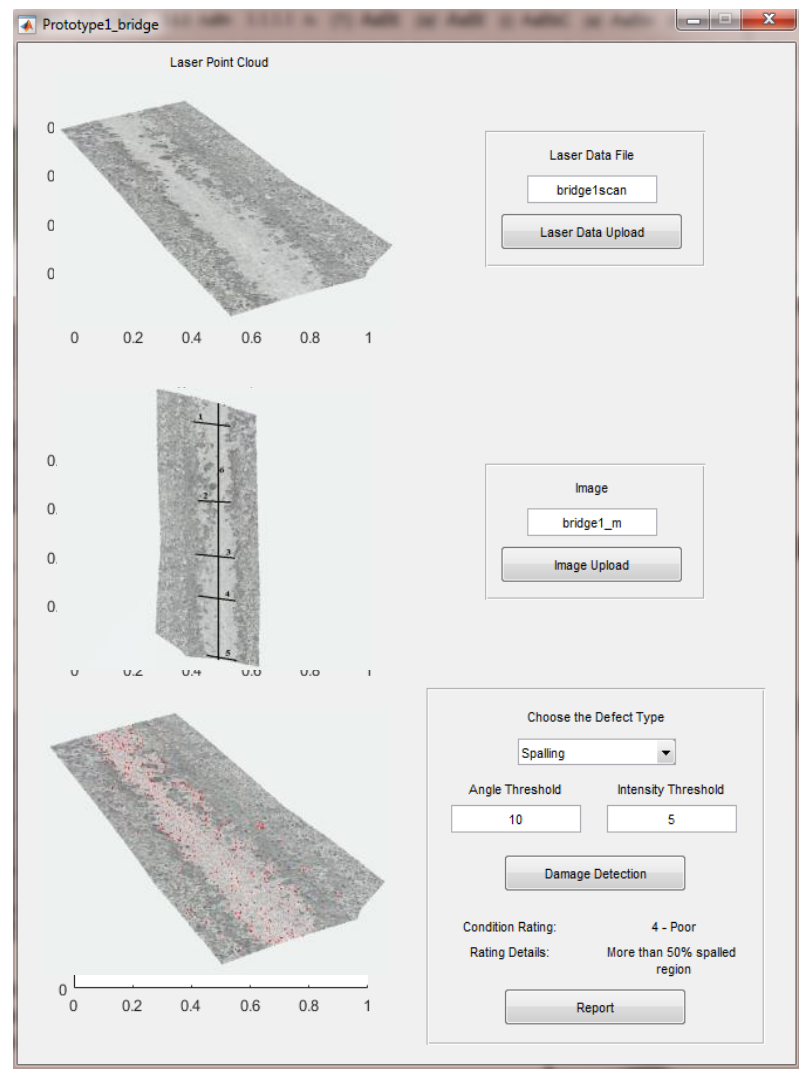

Figure 4: The screenshot of the software prototype that displays the damage detection results of the selected region. 


\begin{tabular}{|c|c|c|c|}
\hline $\begin{array}{c}\text { Measurement } \\
\#\end{array}$ & $\begin{array}{c}\text { Field } \\
\text { Meas. } \\
(\mathrm{mm})\end{array}$ & $\begin{array}{c}\text { Avg. Field } \\
\text { Measurements } \\
(\mathrm{mm})\end{array}$ & $\begin{array}{c}\text { Computed } \\
\text { Dimensions } \\
(\mathrm{mm})\end{array}$ \\
\hline 1 & 208 & & \\
2 & 216 & 230 & 224 \\
3 & 234 & & \\
4 & 262 & 1825 & 1795 \\
5 & 1825 & 1825 \\
\hline
\end{tabular}

Table 2: The comparison between the field measurements and the computed surface damage dimensions.

\section{CONCLUSIONS}

In this paper, the field application of a recently developed software prototype, which is specifically developed for surface damage detection, is discussed. First, information on the software prototype for surface damage detection is presented. Then, the results of the surface damage detection performed on an extracted dataset from Çayırhan Bridge laser point cloud via the developed software prototype, are discussed. The future research will focus on advancing the software for improving the surface damage detection, visualization and reporting capabilities.

\section{ACKNOWLEDGEMENTS}

The authors thank Republic of Turkey Ministry of Transportation and Maritime Affairs and Communication for their contributions to this research. This material is based upon work supported by the Scientific and Technological Research Council of Turkey (TUBITAK) under Grant No. 115C108 and Hacettepe University. Any opinions, findings and conclusions or recommendations expressed in this material are those of the authors and do not necessarily reflect the views of the Scientific and Technological Research Council of Turkey and Hacettepe University.

\section{REFERENCES}

Guldur, B. (2014). "Laser-based Structural Sensing and Surface Damage Detection." Ph.D. Dissertation, Northeastern University, Boston, Massachusetts.

Guldur, B. and Hajjar, J. F. (2014). "Damage Detection on Structures Using Texture Mapped Laser Point Clouds." Proceedings of the ASCE/SEI Structures Congress 2014, Boston, MA.

Guldur Erkal, B. (2017). "The Prototype of a Software Application for Laser and Image-based Surface Damage Detection." 2nd World Congress on Civil, Structural, and Environmental Engineering (CSEE'17), Barcelona, Spain.

Lovas, T., Barsi, A., Detrekoi, A., Dunai, L., Csak, Z., Polgar, A., Berenyi, A., Kibedy, Z. and Szocs, K. (2008). "Terrestrial Laser Scanning in Deformation Measurements of Structures." International Archives of Photogrammetry and Remote Sensing, $37,527-531$.

Ohio Department of Transportation. (2010). "Manual of Bridge Inspection." ORC 5501.47, Ohio Department of Transportation, Columbus, OH, 397 pp.
Olsen, M. J., Kuester, F., Chang, B. J. and Hutchinson, T. C. (2009). "Terrestrial Laser Scanning-based Structural Damage Assessment." Journal of Computing in Civil Engineering, 24(3), 264-272.

Zogg, H. M. (2008). "Investigations of High Precision Terrestrial Laser Scanning with Emphasis on the Development of a Robust Close-range 3D-laser Scanning System." Ph.D. dissertation, Eidgenössische Technische Hochschule (ETH), Zürich, Switzerland. 